\title{
A fatal case of hepatitis B virus (HBV) reactivation during long-term, very-low-dose steroid treatment in an inac- tive HBV carrier
}

\author{
Joong Ho Bae', Joo Hyun Sohn', Hye Soon Lee², Hye Sun Park', Yil Sik Hyun', Tae Yeob Kim¹, Chang Soo Eun', Yong \\ Cheol Jeon', and Dong Soo Han ${ }^{1}$ \\ 'Divisions of Gastroenterology and 2Rheumatology, Department of Internal Medicine, Hanyang University Guri Hospital, Hanyang \\ University College of Medicine, Guri, Korea
}

Hepatitis B virus (HBV) may be reactivated after chemotherapy or immunosuppressive therapy, and therefore administration of antiviral agents before such treatment is recommended. Most reported cases of reactivation are associated with high doses of immunosuppressive agents or combination therapy. We present a case of a previously inactive HBV carrier with an acute severe flare-up during a long-term, very-low-dose ( $2.5 \mathrm{mg} /$ day) steroid treatment for rheumatoid arthritis. We suggest that even a minimal dose of single-regimen oral steroid can cause reactivation of indolent, inactive HBV. (Clin Mol Hepatol 2012;18:225-228)

Keywords: Hepatitis B virus; Liver failure; Steroids; Virus activation

\section{INTRODUCTION}

It is widely accepted that reactivation of hepatitis B virus (HBV) may occur along with an acute hepatitis after chemotherapy or immunosuppressive therapy. ${ }^{1-3}$ Current recommendation is to give antiviral agents before starting these therapies. ${ }^{4-7}$ However, most of the reactivation cases are associated with high doses of immunosuppressive agents including steroids or chemotherapeutic agents. Although there are some case reports of acute flare-up of HBV after high dose steroid therapy, there have been very few reports of acute severe flare-up after long-term administration of low dose steroid in an inactive HBV carrier. Since a vast number of patients are at some point in need of low dose steroid administration, including most rheumatologic diseases such as rheumatoid arthritis (RA), this will be of important concerns in those sectors which low dose steroid is an essential part of prescription. We report a case of previously inactive 86-year-old HBV carrier with an acute severe flare-up during a long term very low dose steroid treatment due to RA, which despite decreased viral activity after prompt initiation of antiviral therapy against HBV, ultimately led to progressive liver failure and death.

\section{CASE REPORT}

In September 2009, a 86-year-old Korean woman visited the out-patient department complaining of recent development of both lower extremity and facial edema. Poor oral intake was evident for nearly a month, and she appeared chronically ill. She was underweight with a body mass index of 18.2 (height 151

\section{Abbreviations:}

DMARD, disease modifying antirheumatic drugs; $H B V$, hepatitis $B$ virus; RA, rheumatoid arthritis; SAAG, serum ascites albumin gradient

\section{Corresponding author : Joo Hyun Sohn}

Division of Gastroenterology, Department of Internal Medicine, Hanyang University Guri Hospital, 153 Gyeongchun-ro, Guri 471-701, Korea Tel. +82-31-560-2225, Fax. +82-31-555-2998, E-mail; sonjh@hanyang.ac.kr 


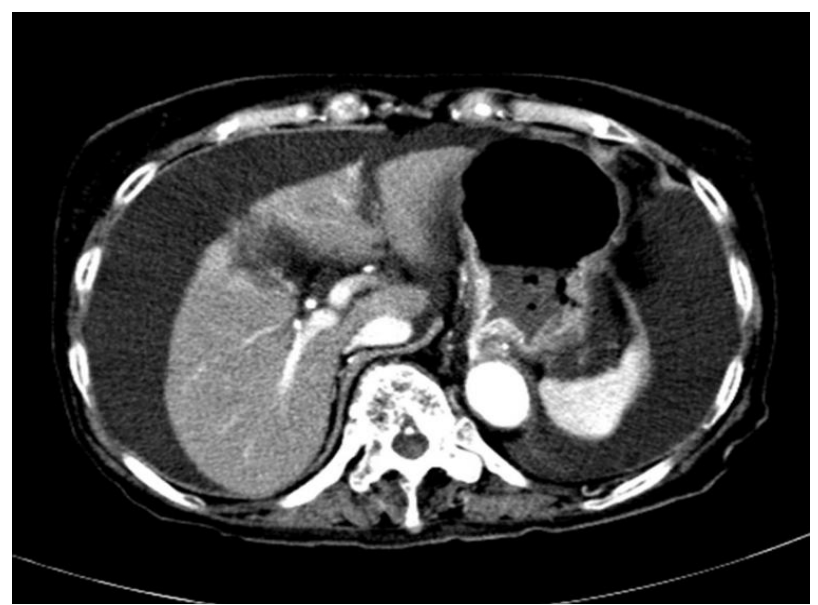

Figure 1. Abdominal CT scan. Note the absence of splenomegaly and formation of collateral vessels, suggesting the low likelihood of portal hypertension. Evidence of liver cirrhosis is not clear, although there is a large volume of ascites.

$\mathrm{cm}$ and weight $41 \mathrm{~kg}$ ). She was previously diagnosed as having RA in November 2006. From the time of diagnosis to September 2009 she made regular visits to the out-patient department of rheumatology and received several treatments consisting of different disease modifying antirheumatic drugs (DMARDs) such as sulfasalazine and hydroxychloroquine, in addition to very low dose oral steroids (2.5 mg/day of prednisone) and COX-2 inhibitor. At that time her serum was positive for $\mathrm{HBsAg}$ and $\mathrm{HBeAb}$ with undetectable HBV DNA ( $<86 \mathrm{IU} / \mathrm{mL}$ ) but negative for $\mathrm{HBs} A b$, HBeAg, and HCV Ab. Serum aspartate aminotransferase (AST) and alanine aminotransferase (ALT) remained persistently normal. All other laboratory tests were unremarkable except a mild degree of anemia (hemoglobin $11.2 \mathrm{~g} / \mathrm{dL}$ ). The follow-up test for liver function obtained at December 2008 was completely within normal limit, with a platelet count of $255 \times 10^{3} / \mathrm{mm}^{3}$. At September 2009, markedly increased HBV DNA titer (> 170,000,000 IU/mL) and abnormal results of liver function tests such as serum ALT 44, AST $76 \mathrm{U} / \mathrm{L}$, total bilirubin $2.0 \mathrm{mg} / \mathrm{dL}$, total protein 5.3 , albumin 2.5 $\mathrm{g} / \mathrm{dL}$, and prothrombin time (PT) $(16.7 \mathrm{sec}, 58 \%$, INR 1.52) were first detected. Platelet count was $134 \times 10^{3} / \mathrm{mm}^{3}$. Serum creatinine level was $0.9 \mathrm{mg} / \mathrm{dL}$, while routine urinalysis revealed no signs of proteinuria or albuminuria. About two weeks later, she was admitted to the department of gastroenterology for further work-up and management. Pitting edema of both lower extremities were evident on physical examination, with mildly distended abdomen. She denied the intake of any other unprescribed medications or alcohol. There were no evidences of hepatitis A and C virus, EpsteinBarr virus, cytomegalovirus, or herpes simplex virus infection. Abdominal ultrasonography revealed a mildly coarse parenchymal

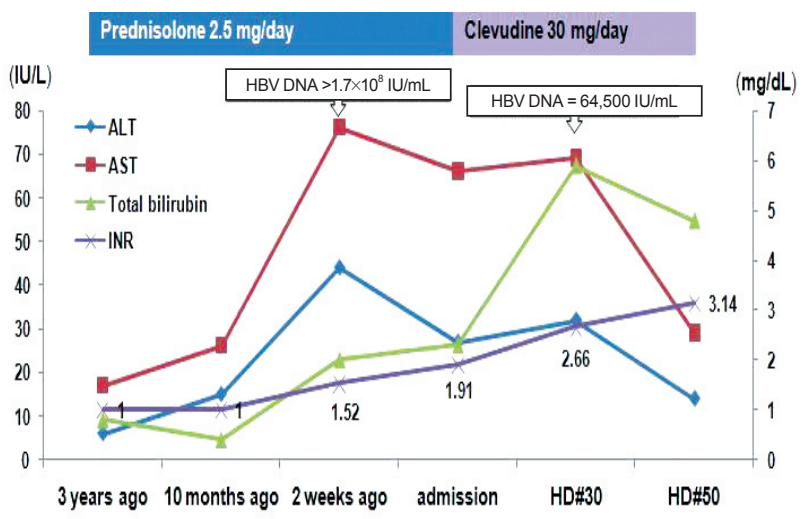

Figure 2. Clinical course of the patient. HD, hospital day.

echogenicity and moderate amount of ascites, with no evidence of liver cirrhosis. Both endoscopy and computed tomography (Fig. 1) also revealed large amount of ascites without signs of portal hypertension. Since her serum and ascites albumin levels at the time of ascites tapping were 2.2 and $0.3 \mathrm{~g} / \mathrm{dL}$ respectively, serum ascites albumin gradient (SAAG) was 1.9, higher than 1.1, indicating that the ascites was transudate. Thus, acute flare-up of hepatitis B caused by HBV reactivation was diagnosed. All DMARDs, COX2 inhibitor and steroid were stopped. Immediate antiviral therapy with clevudine at a daily dose of $30 \mathrm{mg}$ was initiated along with hepatotonics and diuretics. Despite prompt administration of antiviral agent and some virological response toward the reactivated HBV evidenced by a great decrease in HBV DNA titer (64,500 IU/ $\mathrm{mL}$ ) at one month, laboratory tests still revealed elevated levels of AST (69 IU/L) and ALT (32 IU/L), increased total $(5.9 \mathrm{mg} / \mathrm{dL})$ and direct $(3.3 \mathrm{mg} / \mathrm{dL})$ bilirubin, decreased total protein $(4.6 \mathrm{~g} /$ $\mathrm{dL}$ ) and albumin $(2.5 \mathrm{~g} / \mathrm{dL})$, decreased cholesterol (49 mg/dL) and prolonged PT (24.8 sec, 34\%, INR 2.66), aggravated anemia (Hgb $9.0 \mathrm{~g} / \mathrm{dL})$ and first signs of thrombocytopenia $\left(108 \times 10^{3} / \mathrm{mm}^{3}\right)$, indicating the progression of liver failure. Despite continued antiviral administration, liver failure continued to progress (Fig. 2) and multi-organ failure eventually developed, and she died after 50 days since administration of antiviral agent.

\section{DISCUSSION}

HBV infection is by far the most common chronic viral infection affecting the liver in the world, with over 400 million subjects infected, and it is the leading cause of cirrhosis and hepatocellular carcinoma. ${ }^{8}$ Reactivation of HBV replication in patients undergoing immunosuppressive therapy is a well recognized and frequently reported complication of considerable clinical importance. ${ }^{1-3,9-10}$ 
Not surprisingly, most of these reports have come from the fields of oncology and transplantation, but there have been a growing number of cases reported in patients with rheumatic disease undergoing immunosuppressive therapy as well. ${ }^{11-13}$

Among the factors that have been shown to precipitate acute flares of chronic HBV infection is the administration of immunosuppressive drugs. In vitro and in vivo studies clearly indicated that immunosuppression leads to increased HBV replication, assessed by different methods (serum HBV DNA, HBsAg, and HBV DNA polymerase titers). This enhanced replication is attributed to a number of mechanisms, one of which is related to a direct stimulatory effect of these agents on HBV replication. This is particularly the case for corticosteroids, because a corticosteroid responsive element is present in HBV genome and is responsible for increased HBV DNA transcriptional activity and viremia in patients receiving corticosteroids. ${ }^{14}$

Glucocorticoid is implicated as an important predisposing factor for $\mathrm{HBV}$ reactivation. In patients with chronic hepatitis $B$, longterm prednisolone treatment increases levels of $\mathrm{HBsAg}, \mathrm{HBCAg}$, and HBV DNA in hepatocytes, ${ }^{15}$ as well as decreases T-cell function. Immunosuppression is thought to enhance viral replication with a subsequent spread in hepatocyte infection. In addition, glucocorticoids may cause a direct reactivation of the latent HBV infection. ${ }^{16}$ The findings of a glucocorticoid responsive element in HBV genome and the demonstration that glucocorticoids specifically activate HBV gene expression in cultured human hepatocellular carcinoma cells lend support to the direct reactivation theory. ${ }^{16}$ Despite these findings, limited information is available on the effect of the different immunosuppressive regimens given for longer periods of time in lower doses in patients with chronic HBV infection. Data from the long term administration of immunosuppressive drugs in $\mathrm{HBsAg}$ positive renal transplant recipients have shown a high incidence of hepatitis and liver related mortality (10$30 \%){ }^{17}$ There is a paucity of information for other diseases where long term administration of immunosuppression is required-for example, patients with inflammatory bowel diseases, ${ }^{18}$ severe asthma, and various different rheumatic diseases including rheumatoid arthritis. ${ }^{11-13}$

Although there have been some case reports of acute flare-up of HBV after high dose steroid therapy, only a few patients with rheumatic disease and HBV reactivation associated with both non-biological and biological immunosuppressive therapies have been reported. In addition, all of the previously reported HBV reactivation cases with low dose steroid administration have coadministered methotrexate in some degree (varying from $4 \mathrm{mg}$ / week to $15 \mathrm{mg} /$ week), with no reported case of low dose steroid administration alone. It is also worthy to note that the steroid dose administered in the present case was possibly the lowest dose applicable ( $2.5 \mathrm{mg} / \mathrm{day})$. To the best of our knowledge, there has been no previous report of hepatitis B virus reactivation with acute severe flare-up in an inactive hepatitis B virus carrier, especially while taking continuous low dose oral steroid as long as 4-years for maintenance treatment of rheumatoid arthritis. The clinical spectrum of the HBV reactivation can vary from an asymptomatic to acute flare-up and fulminant course. HBV reactivation leading to a fulminant course is a serious condition and results in death or transplantation in most cases. In this situation, the goals of aggressive antiviral therapy prevent the need for liver transplantation, decrease post-transplantation HBV recurrence, and sustain viral suppression and viral activity reduction. ${ }^{19}$ The patient was not a candidate for transplantation, and we immediately decided to initiate antiviral treatment.

Although the patient underwent prompt antiviral treatment with clevudine, and despite some response toward the viral activity, the liver function gradually failed, ultimately leading to multiorgan failure and death.

The limitation of this case could be that spontaneous reactivation of HBV cannot be wholly excluded. Moreover, since the patient was visiting only the department of rheumatology at a regular base, the viral markers and HBV DNA which represents the activity of the HBV were not recorded as often as it should have been. However, since the incidence of such spontaneous reactivation of HBV is very rare in an old-aged patient such as in this case, and the fact that viral load of the patient surged dramatically, it suggests that the etiology of HBV reactivation may be long-term steroid administration. It is also true to say that the possibility of inactive cirrhosis cannot be fully excluded, in which steroid administration might have caused a fatal HBV reactivation.

Our case suggests that even an administration of non-combination, minimal dosage of single oral steroid can cause reactivation of indolent, inactive HBV. Since a vast number of patients are at some point in need of low-dose steroid administration, including most rheumatologic diseases such as rheumatoid arthritis, this will be of important concerns in the sectors where low dose steroid is an essential part of prescription.

In conclusion, in an inactive HBV carrier, if a long-term administration of steroid is planned, an adequate evaluation of the liver function and disease status should be evaluated by specialists. Once steroid has been administered, regular HBV DNA monitoring is mandatory, and early antiviral therapy is required if the serum 
HBV DNA level begins to rise, which may lead to serious liver damage.

\section{Conflicts of Interest}

The authors have no conflicts to disclose.

\section{REFERENCES}

1. Lok AS, Liang RH, Chiu EK, Wong KL, Chan TK, Todd D. Reactivation of hepatitis $B$ virus replication in patients receiving cytotoxic therapy. Report of a prospective study. Gastroenterology 1991;100:182-188.

2. Fukushima N, Mizuta T, Tanaka M, Yokoo M, Ide M, Hisatomi T, et al. Retrospective and prospective studies of hepatitis $B$ virus reactivation in malignant lymphoma with occult HBV carrier. Ann Oncol 2009;20:2013-2017.

3. Pei SN, Chen CH, Lee CM, Wang MC, Ma MC, Hu TH, et al. Reactivation of hepatitis $B$ virus following rituximab-based regimens: a serious complication in both $\mathrm{HBsAg}$-positive and $\mathrm{HBsAg}$-negative patients. Ann Hematol 2010;89:255-262.

4. Lau GK, Yiu HH, Fong DY, Cheng HC, Au WY, Lai LS, et al. Early is superior to deferred preemptive lamivudine therapy for hepatitis B patients undergoing chemotherapy. Gastroenterology 2003;125:1742-1749.

5. Yeo W, Johnson PJ. Diagnosis, prevention and management of hepatitis $B$ virus reactivation during anticancer therapy. Hepatology 2006;43:209-220.

6. Francisci D, Falcinelli F, Schiaroli E, Capponi M, Belfiori B, Flenghi L, et al. Management of hepatitis $B$ virus reactivation in patients with hematological malignancies treated with chemotherapy. Infection 2010;38:58-61.

7. Lubel JS, Angus PW. Hepatitis B reactivation in patients receiving cytotoxic chemotherapy: diagnosis and management. J Gastroenterol Hepatol 2010;25:864-871.

8. Lai CL, Ratziu V, Yuen MF, Poynard T. Viral hepatitis B. Lancet
2003;362:2089-2094.

9. Perrillo RP. Acute flares in chronic hepatitis B: the natural and unnatural history of an immunologically mediated liver disease. Gastroenterology 2001;120:1009-1022.

10. Vento $S$, Cainelli F, Longhi MS. Reactivation of replication of hepatitis $B$ and $C$ viruses after immunosuppressive therapy: an unresolved issue. Lancet Oncol 2002;3:333-340.

11. Calabrese LH, Zein N, Vassilopoulos D. Safety of antitumour necrosis factor (anti-TNF) therapy in patients with chronic viral infections: hepatitis C, hepatitis B, and HIV infection. Ann Rheum Dis 2004;63(Suppl 2):ii18-ii24.

12. Tur-Kaspa R, Burk RD, Shaul Y, Shafritz DA. Hepatitis B virus DNA contains a glucocorticoid-responsive element. Proc Natl Acad Sci U S A 1986;83:1627-1631.

13. Chung SJ, Kim JK, Park MC, Park YB, Lee SK. Reactivation of hepatitis B viral infection in inactive HBsAg carriers following anti-tumor necrosis factor-alpha therapy. J Rheumatol 2009;36:2416-2420.

14. Kim YJ, Bae SC, Sung YK, Kim TH, Jun JB, Yoo DH, et al. Possible reactivation of potential hepatitis $B$ virus occult infection by tumor necrosis factor-alpha blocker in the treatment of rheumatic diseases. J Rheumatol 2010;37:346-350.

15. Lam KC, Lai CL, Trepo C, Wu PC. Deleterious effect of prednisoIone in HBsAg-positive chronic active hepatitis. N Engl J Med 1981;304:380-386.

16. Chou CK, Wang LH, Lin HM, Chi CW. Glucocorticoid stimulates hepatitis B viral gene expression in cultured human hepatoma cells. Hepatology 1992;16:13-18.

17. Rossi G. Prophylaxis with lamivudine of hepatitis B virus reactivation in chronic HbsAg carriers with hemato-oncological neoplasias treated with chemotherapy. Leuk Lymphoma 2003;44:759-766.

18. Biancone L, Del Vecchio Blanco G, Pallone F, Castiglione F, Bresci G, Sturniolo G. Immunomodulatory drugs in Crohn's disease patients with hepatitis B or C virus infection. Gastroenterology 2002;122:593-594.

19. Roche B, Samuel $D$. The difficulties of managing severe hepatitis $B$ virus activation. Liver Int 2011;31(Suppl 1):104-110. 